\title{
Management of cholestasis in unusual social conditions: a case report
}

\section{A.V.Antoci ${ }^{12}$, A. Coroleuca ${ }^{12}$, A. Poparlan 1 , D. Pacurar ${ }^{12}$}

1. Emergency Hospital for Children "Grigore Alexandrescu", Bucharest

2. "Carol Davila" University of Medicine and Pharmacy, Bucharest

\section{INTRODUCTION}

Cholestasis is still a significant cause morbidity and mortality in young infants. Establishing diagnosis and management may turn out more challenging than expected.

\section{CASE REPORT}

A two and a half months old infant was transferred in our clinic for:

- persistent jaundice - pale stools - dark urine.

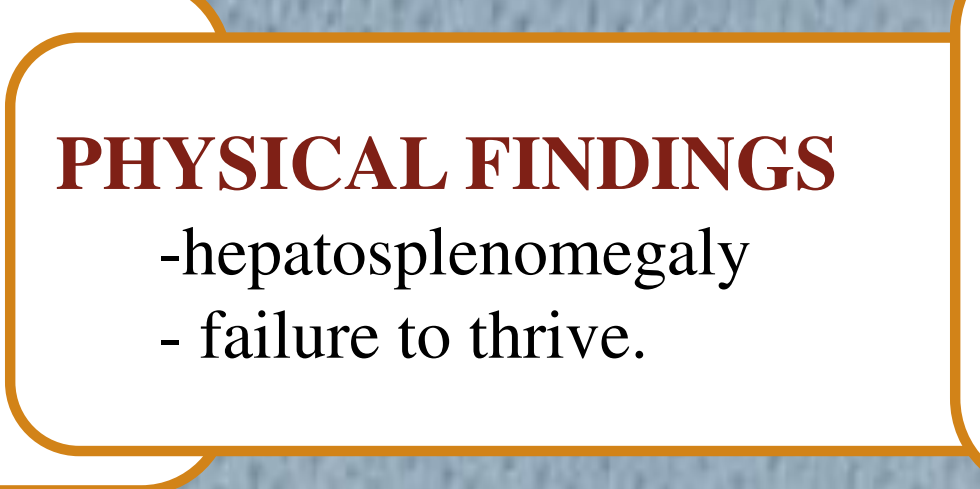

INITIAL LABORATORY TESTS

elevated aminotransferase

conjugated hyperbilirubinemia

- elevated gamma-glutamyltransferase

hypoalbuminemia.

\section{ABDOMINAL ULTRASONOGRAPHY \\ - a small gallbladder \\ - the common bile duct - not visible \\ - the intrahepatic biliary tree- slightly dilated.}

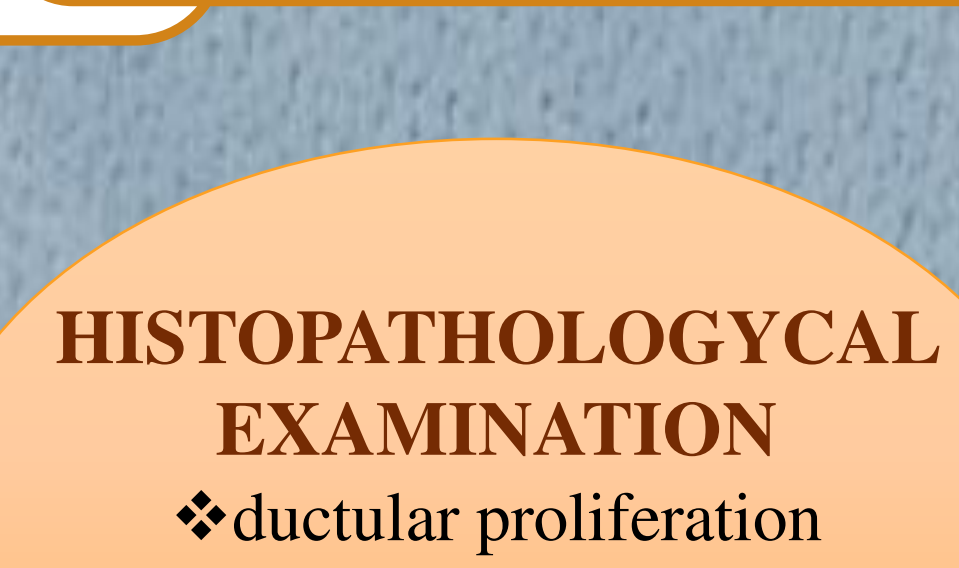

* bile duct and ductular bile plugs portal fibrosis
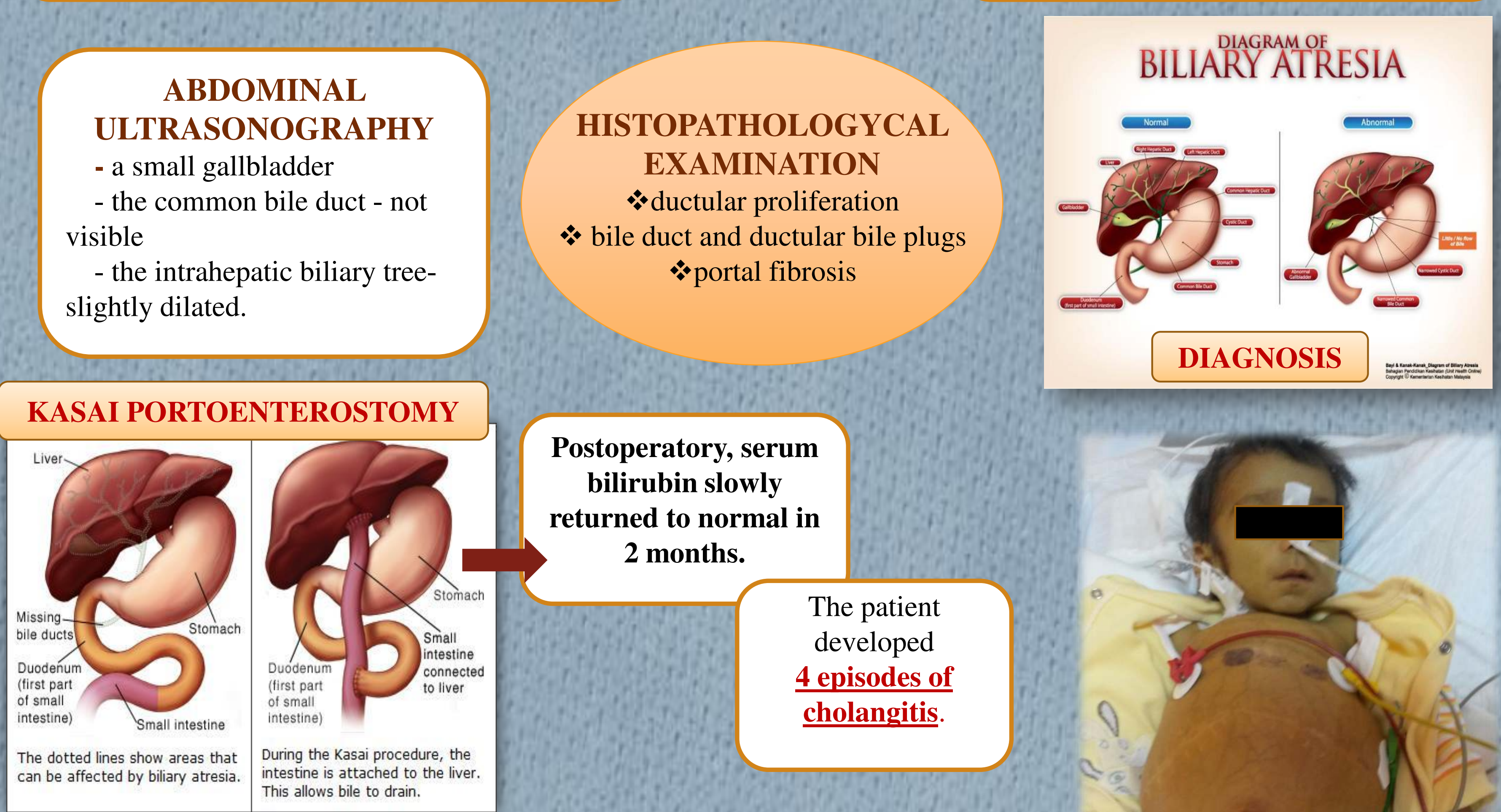

Postoperatory, serum bilirubin slowly returned to normal in 2 months.

\section{We find ourselves in front of a patient with: \\ -recurrent cholangitis \\ - intractable ascites \\ INDICATION OF LIVER TRANSPLANT PELD score $=18.7$}

-biliary cirrhosis with portal

hypertension

-decreased hepatic synthetic

function,

-growth failure

-in the care of Social Services.

\section{CONCLUSIONS}

The patient developed

4 episodes of cholangitis.

89.4\% rate of survival 1 year after transplant

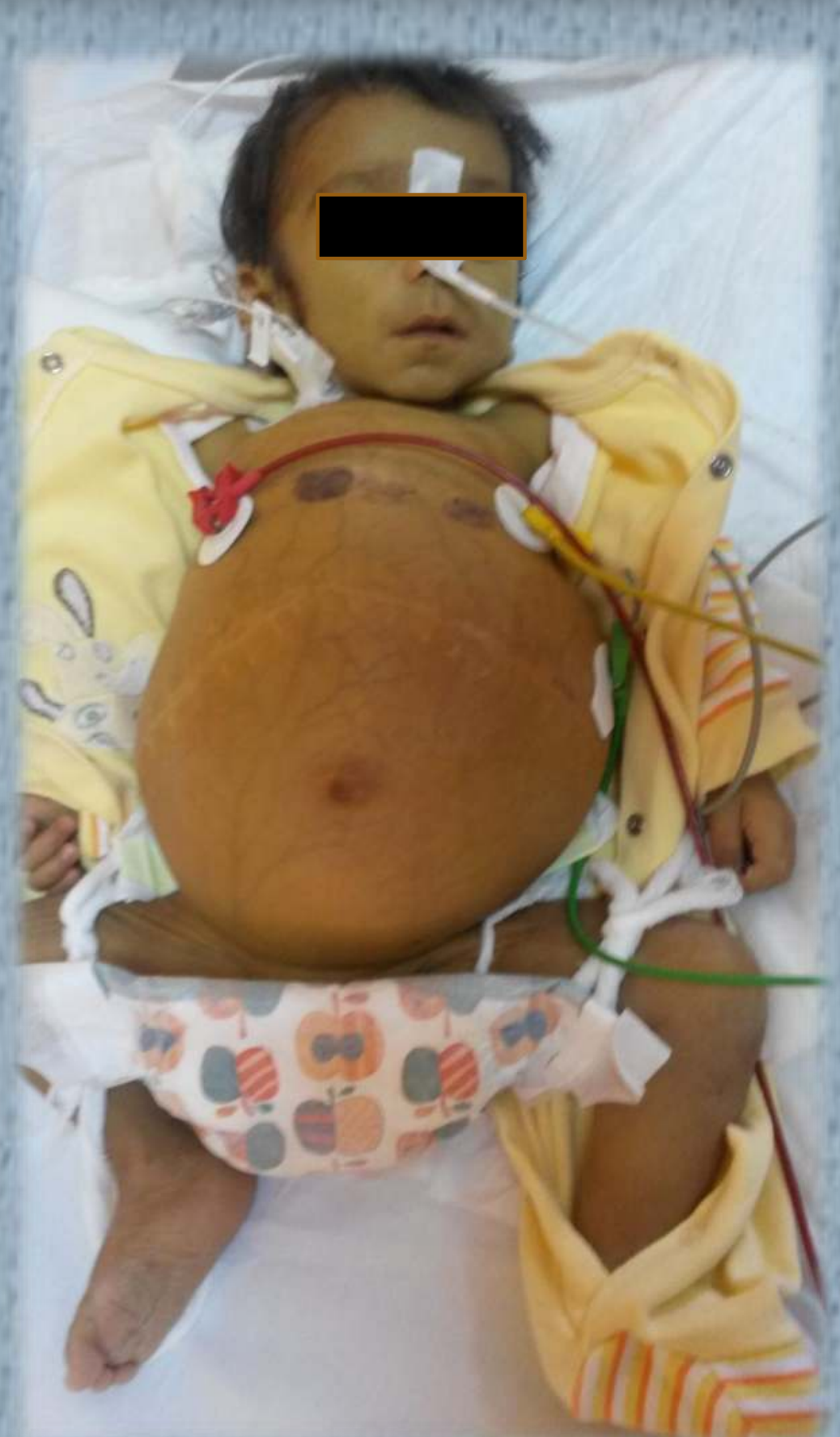

At the moment, the lack of a legal guardian to consent the transplant and support long-term medical care makes the patient ineligible for a liver transplant.

Socioeconomic factors can make management of cholestasis more challenging than it looks. 